\title{
FACTORS AFFECTING THE WORK MOTIVATION OF OFFICERS IN THE ROMANIAN ARMY
}

\author{
Crenguța Mihaela MACOVEI*
}

mihaela.macovei1@gmail.com

Lucian Marian ARGINTARU**

lucian_marian94@yahoo.com

* “NICOLAE BĂLCESCU” LAND FORCES ACADEMY, SIBIU, ROMANIA

**U.M. 01495 CINCU, ROMANIA

\begin{abstract}
:
This paper presents the results of a study in which we aimed to identify factors that influence the work motivation of officers active in the Romanian military system. We developed a hierarchy of these factors depending on the frequency of their occurrence in answers to open questions addressed on this issue. In order to process responses we used the Atlas.ti program, a specialized software in qualitative analysis of large corpora of text, graphs, audio and video materials. Seven factors have been identified that increase the motivation to work and nine factors that decrease the work motivation of officers from the selected sample.
\end{abstract}

\section{KEYWORDS:}

Work motivation, military system, content analysis

\section{Introduction}

In the military organization, as in any other organization, the human factor is the key to achievements and performance.

The military organization remains an institution with its own way of organization, leadership and hierarchy, with specific characteristics such as strictness, formal relations, behavioral restrictions, and danger related to specific military activities, all of which influencing the way a person becomes motivated to accede to this system, to prepare as a specialist and build a career for a long time. The evolution in the military career requires performance in previous positions, skills for the next position and potential to develop career; all this cannot be sustained without proper motivation.

As in other areas, military activity is 
guided by a complex motivation. These reasons vary from person to person, as the case may be intrinsic or extrinsic and are influenced by type of work, type of personality, the working environment, relationships with subordinates, peers or commanders etc. The military organization in itself creates a framework with specific stimuli and particular work situations, which triggers specific organizational behaviors, in combination with individual characteristics.

Based on proposals from authors who have published in this field, M. Zlate (2007) set out three main categories of organizational stimuli with motivational value:

1. The economic stimulus type (fiscal and material stimulus) - salary, benefits, awards etc;

2. Professional stimulus type - work and working conditions, including its purpose;

3. Psychosocial stimuli - working group interactions, structure, purpose or group size etc.

Motivation "is designated as the body's internal state of necessity which guides and directs behavior toward satisfying it and thus towards removing it" (M. Zlate, 2007, p. 387). It speaks about a chain of needs, tendencies, desires, impulses that mobilize, activate and induce the person to perform a certain behavior that should lead to their adequate satisfaction.

Bogathy Z. (2004) shows that, in the context of occupational psychology, motivation can be defined as all internal and external energies that initiate, direct and support efforts towards attaining an organizational goal that will simultaneously satisfy individual necessities.

C.C. Pinder proposes the following definition: "Work motivation is a set of energetic forces that originate both within as well as beyond an individual's being, to initiate work-related behavior, and to determine its form, direction, intensity and duration" (Pinder, 2008, p.11).

G.P. Latham \& C.C. Pinder (2005) conducted a review of the progress made between 1993 and 2003 in developing theories and research on work motivation. Beyond the classical approaches that focus on the role of needs, traits, values, emotions and cognition in determining motivation at work, these two authors discuss the role of important variables such as national culture, job design, and models of personenvironment fit. The authors also remarked that modern theories on motivation that imposed themselves and developed are goal-setting, social, cognitive, and organizational justice theories.

J.J. Donovan (2001) observed that modern theoretical models of motivation at work - Goal-Setting Theory, Control Theory, and Social Cognitive Theory have a high degree of consistency because all three emphasize the importance of goals as primary determinants in self - regulatory processes underlying work motivation.

$\mathrm{XXI}^{\text {st }}$ century begins with an increased focus on the role of emotions in shaping employee behavior at work. There is also significant concern about the ability of theoretical models to make appropriate predictions on employee motivation, taking into account the interaction between cognition (mainly represented by goals), affect (represented mainly by emotions) and behavior.

Another significant trend is the study of the influence of national culture on work motivation, which enables inter-cultural understanding of differences in this area (Latham \& Pinder, 2005).

\section{Method}

We aimed to identify factors that influence the work motivation of officers active in the Romanian military system and realize a hierarchy depending on the frequency of their occurrence in a set of answers to open questions on the subject. Therefore, 80 Romanian Army officers were asked to fill with as much detail as possible, the following sentences:

"What increases my motivation to work is ",

work is

"What reduces my motivation to 66 
The program used to analyze responses was Atlas.ti, a software specialized in qualitative analysis of large portions of text, graphs, audio and video materials. It contains many tools that allow the researcher to explore in depth and combine materials that it wishes to consider in various ways.

We transcribed the officer's answers into a Word document that was introduced as the primary document in the Atlas.ti program. Within the document, "quotations" were created by selecting segments of those answers - isolated words, groups of words or sentences - that have significance for our research purposes. We assigned a code to each "quotation"; some "quotations" enrolled under several codes simultaneously, which generated co-occurences. We grouped the codes into a family of codes; hence, we got the two families of codes graphically represented in this paper. We also represented the links between codes, within each family, using the Atlas.ti program tool offered by Network View Manager.

The hierarchy of factors that increase the motivation of officers surveyed is as follows:

1. Work characteristics with a total of 22 responses, extremely varied: the work itself, instruction and practical activities, the lack of monotony, a work strategy, a clear purpose, clear and concise goals that should lead to the aim achievement, the pleasure offered by specific activities, wellness consecutive to solving difficult situations, participation in exciting activities, exercises and joint training with other similar structures, ability to see the outcomes of their labor, participation in joint exercises and the opportunity to participate in international missions, fixed work schedule, working with people;

2. The possibility of professional achievement with 20 responses: the opportunity to participate in training and professional development programs or activities, joint exercises with other similar structures, the chance to go to international missions, the ability to improve as military, the satisfaction of sharing knowledge gained and the opportunity to shape character by the nature of the activities, satisfaction of a job well done and the immediate results of labor, increasing the level of training by practice, participation in joint exercises, the opportunity to take part in international exercises and work with soldiers in other countries, fairness of the career advancement system, opportunities for career development, opportunity for specialized military training, professional fulfillment and satisfaction;

3. The climate in the workplace, with 17 responses, refers to the workplace atmosphere, the pleasure of working in teams and teamwork generated by a high degree of cohesion;

4. Merit recognition by both superiors and colleagues, resulting in the appreciation and respect of others and the subsequent state of personal satisfaction (16 responses);

5. The possibility of personal development (14 responses); this category includes issues such as satisfaction to gain new skills and meet new people, personal training in order to acquire information on specific activities and their implementation within multinational exercises, passion and dedication to the field of activity, fear of capping.

Promotion opportunities (13 responses), job security (11 responses) and material rewards (9 responses) are also factors that increase the motivation of officers in the sample. The code family structure is shown in Figure no. 1.

The hierarchy of factors that decrease work motivation of questioned officers is as follows:

1. Working conditions (36 responses); this category includes complaints about outdated equipment and poor material facilities of the workplace, lack of personnel resulting in clutter with additional tasks, the improper workplace design;

2. Commanders behavior, with a total of 25 responses; this category includes behaviors such as: pressure unnecessarily exercised over subordinates, with direct 
effects on stress felt by them, the failure to recognize merit of subordinates, subjectivity, lack of seriousness or lack of confidence in relations with subordinates, lack of interest in real communication or lack of communication skills, lack of desire or ability of superiors to collaborate with subordinates, orders received simultaneously from different hierarchical levels, excessively authoritarian behavior, incorrect distribution of tasks;

3. Failure to recognize merit (19 responses), by superiors and co-workers; this factor also includes other behaviors such as advantaging some colleagues on criteria other than competence associated with the presence of a system of informal relations which overlaps and influences the formal one, the lack of objective evaluation, the lack of appreciation and recognition of additional effort;

4. Inadequate remuneration

(14 responses); this category includes complaints of the military regarding weak remuneration, wage cuts and reduction of benefits, lack of staff which entails a high volume of work is not rewarded, the inequitable distribution of workload in terms of identical remuneration, remuneration lower than the high degree of responsibility associated to some positions, the lack of material or financial rewards for extra effort or outstanding results;

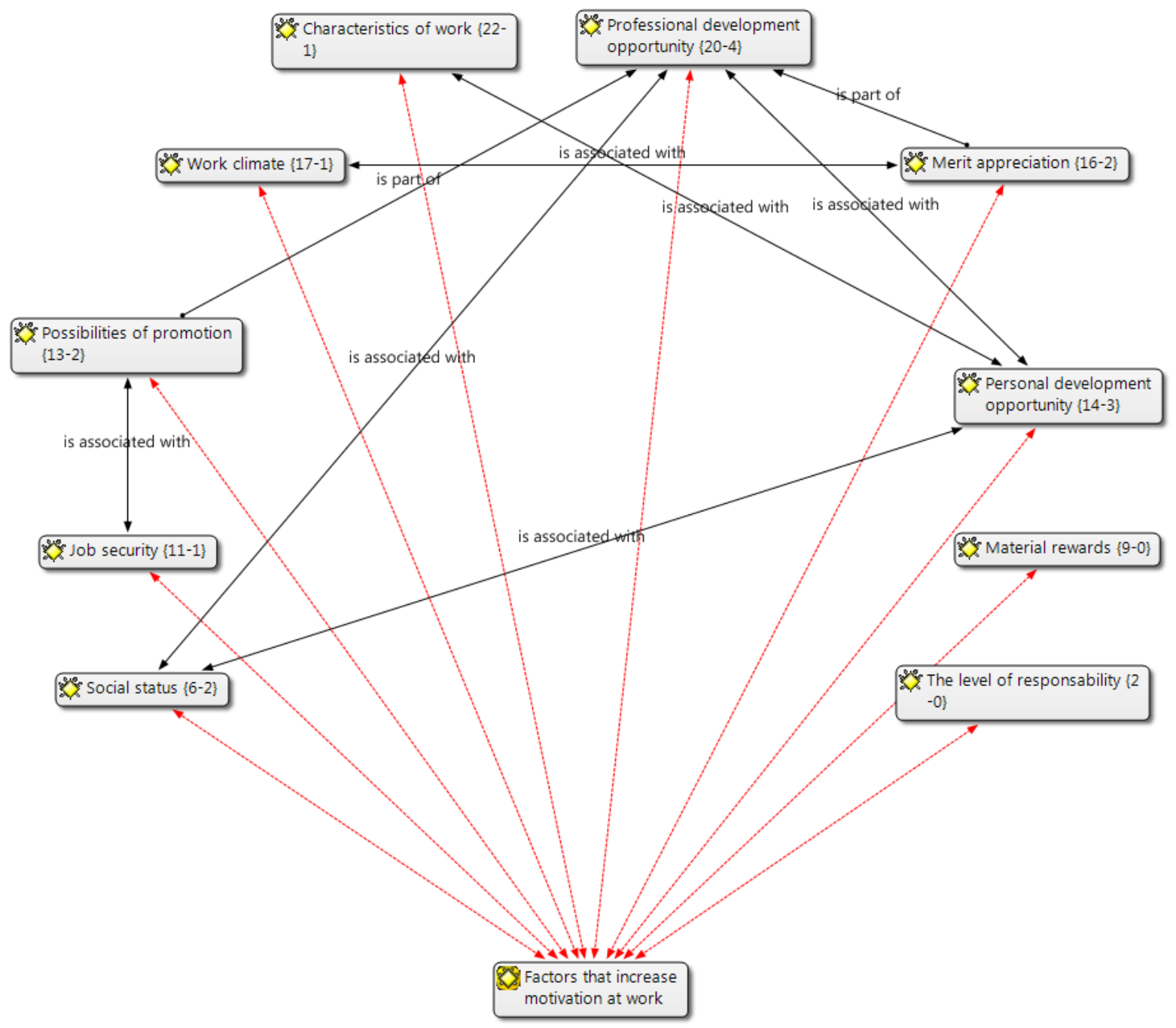

Figure no. 1. The family of codes Factors that increase the work motivation of officers 
5. The behavior of co-workers is a factor closely related to another one that is on the same level of importance as the lack of task cohesion (each with 12 responses); the two co-occurrent codes will be treated together and we will include here aspects of both categories:

lack of interest from colleagues and subordinates to daily work, the fact that each sees his "own interest", the lack of motivation for active participation to the actions of the unit, the condescending behavior of officers from indirect pathway, the phenomenon of social loafing, not taking responsibility when needed or when making mistakes, the lack of involvement both in the daily activities and in the exceptional ones, the lack of professionalism of some colleagues, the lack of collaboration;

The stress as a general factor is the following in this hierarchy, generated by all the elements listed above (7 responses). Inequity (6 responses) is a factor closely linked to the behavior of superiors and colleagues and is manifested in part by the failure to recognize merits. Finally, the work climate and bureaucracy are factors mentioned as such in five and respectively in two questionnaires.

The structure of this code family is shown in Figure no. 2.

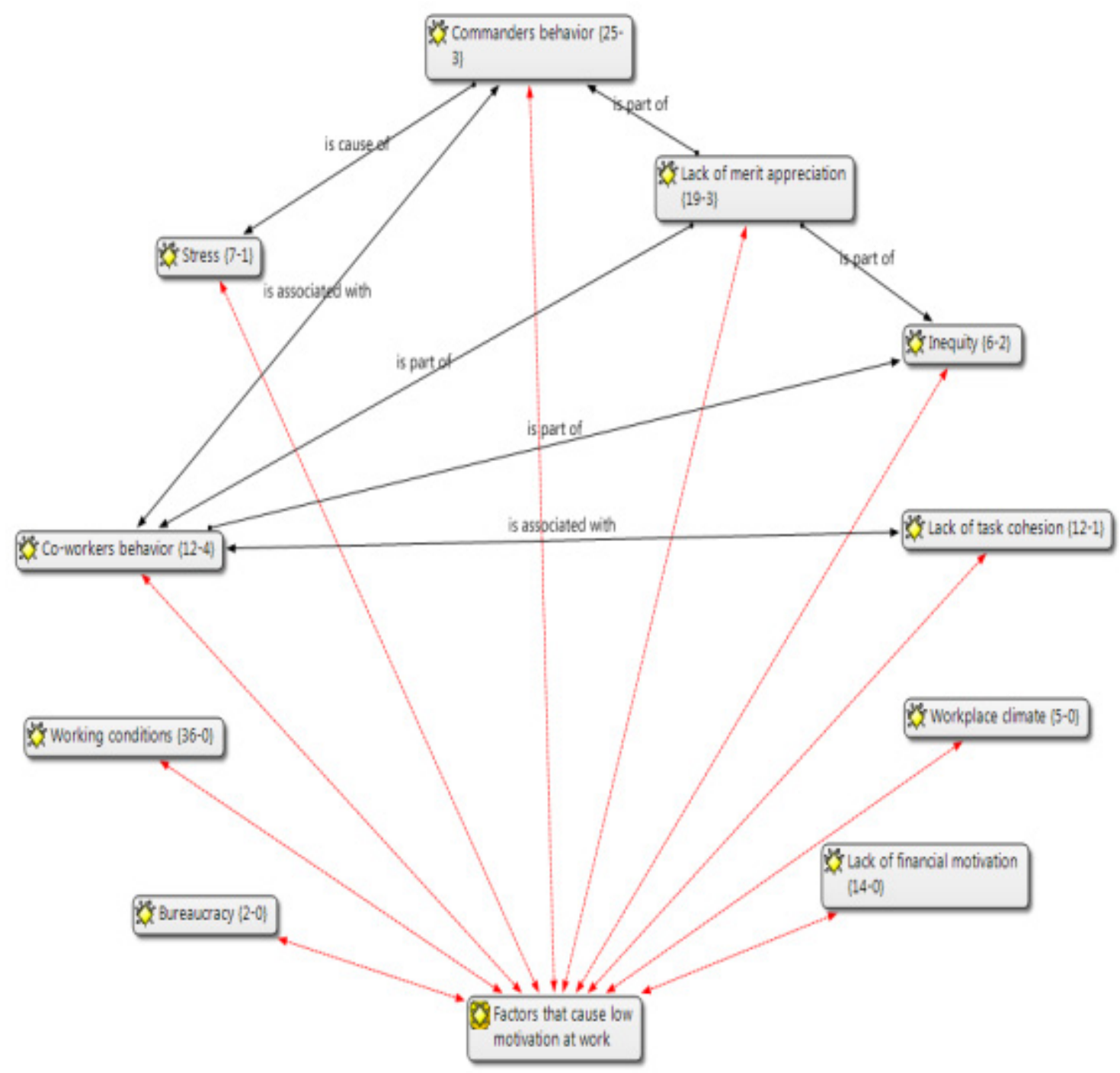

Figure no. 2. The family of codes Factors that decrease the work motivation of officers 


\section{Discusion}

We started our research without relating to a particular theory and we formulated two items to which officers responded freely, without receiving any indication from researchers. After assigning codes and setting relations between them, it became very clear that we could relate to the theory of Herzberg's hygienic motivation. Characteristics of employment, the professional development opportunity, merit recognition by superiors and colleagues, the opportunity to develop as a person and promotion opportunities are motivators in the daily work of officers.

Working conditions, commander's behavior, the lack of appropriate remuneration, workmates behavior, lack of task cohesion, stress, inequity, failure to recognize merit, work climate and bureaucracy are hygienic factors, whose presence create dissatisfaction and these decrease work motivation.

However, the officers who responded to our questions placed in the motivating factor category three factors considered by Herzberg as hygienic. These are "climate in the workplace", "job security" and "material rewards". It is possible that some of the officers surveyed prefer the combination High hygiene + Low motivation, these being rather employees who see workplace as a paycheck, but have few complaints and few incentives and low expectations.

Given the wording of items, at first glance, one would have thought that the answers of officers will be "mirrored" in the sense that the opposite of the factors appearing as motivators should appear as factors that decrease motivation. As we have seen, the case of a single factor, namely "merit recognition", which appears to be a significant problem for motivation at work in the sample researched. Respect and appreciation of colleagues and superiors for their work and the results obtained are issues of intrinsic motivation. Workmates and the way they relate to each other and to their work influences the climate in the workplace, with direct effect on employee productivity (Mathews \& Khann, 2016). Merit recognition by commanders also increases motivation and productivity of subordinates and influences their perception regarding organizational policies, which have a significant effect on employee turnover and retention (Chipunza \& Samuel, 2009).

\section{Conclusion}

In modern organizations, the motivation process requires a response to the specific needs of employees with direct effect on productivity, performance and satisfaction in their work.

Modern armies need flexible staff, highly qualified, grouped into units that could be deployed quickly and can use modern technology in a professional manner. Technology has influenced to a considerable extent the way a modern military organization "works", with direct effect on the military management. Today there is a focus on the development of military skills to manage resources and coordinate efforts at every tactical level. Modern military organization becomes a knowledge based organization where the positive command climate plays an important role; such a climate can be created only if military leaders engage in a dialogue with subordinates and interact with them based on principles that stimulate self-management, personal development, commitment and not in the least the intrinsic motivation at work. 


\section{REFERENCES}

Polirom.

Bogathy, Z. (2004). Manual de psihologia muncii şi organizaţională, Bucureşti: Editura

Donovan, J.J. (2001). Work Motivation, in Neil Anderson, N., Ones, D.S., Sinangil, H.K. \& Viswesvaran, C. (eds), Handbook of Industrial, Work and Organizational Psychology. Volume 2: Organizational Psychology, 53-76.

Latham, G.P. \& Pinder, C.C. (2005). Work motivation theory and research at the dawn of the twenty-first century, Annu. Rev. Psychol. $56: 485-516$.

Mathews, C. \& Khann, I.K. (2016). Impact of Work Environment on Performance of Employees in Manufacturing Sector in India: Literature Review, International Journal of Science and Research (IJSR), Volume 5, Issue 4.

Pinder, C.C. (2008). Work Motivation in Organizational Behavior, Second Edition, New York: Psychology Press.

Samuel, M.O. \& Chipunza, C. (2009). Employee retention and turnover: Using motivational variables as a panacea, African Journal of Business Management Vol.3 (8), 4, 10-415.

Sava, F. (2007). Politicile motivaţionale, in Bogathy, Z. (coord.), Manual de tehnici şi metode în psihologia muncii şi organizaţională, Iaşi: Polirom, 317-328.

Zlate, M. (2007). Tratat de psihologie organizaţional-managerială, Volumul al II-lea, Iaşi: Editura Polirom. 